\title{
Desenvolvimento local em destinos turísticos alternativos: Estação Náutica de Avis (Alentejo - Portugal)
}

\author{
Paula Reis* \\ Instituto Politécnico de Castelo Branco | CICS.NOVA.UÉvora (Portugal) \\ Ana Balão** \\ CICS.NOVA.UÉvora (Portugal) \\ Maria da Saudade Baltazar*** \\ Universidade de Évora | CICS.NOVA.UÉvora (Portugal) \\ Marcos Olímpio dos Santos**** \\ CICS.NOVA.UÉvora (Portugal)
}

\begin{abstract}
Resumo: O artigo visa apresentar um estudo de caso sobre estratégias de desenvolvimento local, centrado no turismo náutico, e que está em curso num território do interior, em Avis, na regiãoAlentejo (Portugal). Amobilização e envolvimento dos atores territoriais, no aproveitamento e valorização dos recursos endógenos, para a construção de um produto turístico integrado, num destino alternativo, conseguiu-se mediante aplicação da metodologia world café, assumindo um carácter inovador e comprovadamente profícuo.Os resultados alcançados fomentaram o interconhecimento e espírito de equipa (team bulding), num processo de quadrupla hélice, articulando diversos produtos locais para a estruturação do produto turístico integrado - Estação Náutica de Avis. Verificou-se, assim, que a adoção de metodologias participativas desempenham uma função estruturante constituindo-se como fator crítico de sucesso nos processos de desenvolvimento. A mais-valia deste artigo consiste na partilha destas metodologias a incorporar em setores de atividade específicos como o turismo e outros domínios de intervenção.
\end{abstract}

Palavras-chave: Desenvolvimento local; Turismo náutico; Metodologia participativa; Produto turístico; Destinos alternativos.

\section{Local development in alternative tourist destinations: Avis Nautical Station (Alentejo - Portugal)}

Abstract: The objective of this article is to present a case study focusing on local development strategies of nautical tourism, currently underway in an inland territory, in the municipality of Avis in the Alentejo region (Portugal). The necessary mobilisation and involvement of the local stakeholders, in the use and valorisation of their endogenous resources toward the construction of an integrated tourist product,in an alternative tourist destination, has been achieved through the application of the world café methodology, which in this case proved to be innovative and fruitful. The results achieved fostered inter-knowledge and the formation of teams working together in a four-helix process, articulating several local products toward structuring the integrated tourist product - Avis Nautical Station. We have seen how participative methodologies assume a structuring role, critical to success in the development processes. The added value of this article consists in sharing these methodologies toward their incorporation in specific sectors of activity such as tourism and other areas of intervention.

Keywords: Local development; Nautical tourism; Participatory methodology; Tourism product; Alternative destinations.

\footnotetext{
Instituto Politécnico de Castelo Branco I CICS.NOVA.UÉvora (Portugal); E-mail: paula.reis@ipcb.pt; https://orcid.org/0000$-0002-0258-8990$

** CICS.NOVA.UÉvora (Portugal); E-mail: ana.balao@hotmail.com; https://orcid.org/0000-0003-3744-3764

*** Universidade de Évora | CICS.NOVA.UÉvora (Portugal); E-mail: baltazar@uevora.pt; https://orcid.org/0000-0002-2995-820Xx

**** CICS.NOVA.UÉvora (Portugal); E-mail: mosantos@uevora.pt; https://orcid.org/0000-0002-4166-7026
} 


\section{Introdução}

A especificidade dos territórios do interior de Portugal (cerca de 70\% do continente), também denominados de baixa densidade, tende a reforçar-se num processo de causalidade circular cumulativo, particularmente os de localização geográfica periférica e predominantemente rurais, que se constituem como territórios regressivos em várias componentes (marcadamente demográfica, económica e infraestrutural) cujo desenvolvimento futuro é determinado por fatores internos (forças e fraquezas) e externos (oportunidades e ameaças).

Não obstante os constrangimentos com que confrontam estes territórios, os seus responsáveis têm vindo a envidar esforços no aproveitamento dos recursos endógenos, promovendo condições para que sejam concretizadas iniciativas de desenvolvimento de base local.

Neste artigo é descrito o processo a decorrer no concelho de Avis (Alentejo - Portugal), onde se encontra em desenvolvimento um produto turístico integrado - a Estação Náutica de Avis -, cuja metodologia de lançamento é descrita e analisada criticamente.

Este estudo de caso proporcionou a oportunidade de refletir sobre conceitos e práticas inerentes aos processos de desenvolvimento local em territórios de baixa densidade, no passado e na atualidade, no contexto das políticas públicas (regionais, nacionais e europeias) mas também sobre novas procuras e novas funcionalidades económicas, nomeadamente o lazer e o turismo.

Transmitir essa experiência, na sua vertente técnico-científica constitui uma motivação que é transposta para o presente texto, o qual tem como objetivo apresentar a descrição crítica das aprendizagens obtidas com a aplicação de estratégias de desenvolvimento integrado centrado no turismo náutico, num destino turístico alternativo.

Os resultados da pesquisa e os procedimentos adotados para os alcançar são apresentados ao longo dos seguintes pontos: i) revisão da literatura (parte em que se traça o enquadramento teórico-conceptual); ii) apresentação do estudo de caso (onde se expõe de forma detalhada a experiência e os seus atores); iii) metodologia (apresentação das opções metodológicas, sistematização e análise dos resultados obtidos).

$\mathrm{O}$ artigo culmina com a apresentação de um conjunto de considerações que emergiram durante a realização da pesquisa, complementadas com as reflexões efetuadas sobre o trabalho realizado.

\section{Revisão da literatura}

Nas últimas décadas os territórios rurais do mundo ocidental ganharam amplo destaque no quadro conceptual das novas perspetivas de desenvolvimento, na agenda política e mediática e no contexto das políticas públicas europeias e nacionais, em virtude de profundas transformações. Essas transformações territoriais têm contudo raízes profundas sedimentadas em processos de natureza demográfica, socioeconómica, política, cultural e institucional em múltiplas áreas, sendo exemplo disso a perda de vitalidade dos territórios do arco interior no contexto nacional (Correia \& Carvalho, 2010; Carmo, 2014; Reis, 2017; Baltazar, 2018). Não é menos verdade que a indiscutível perda de vitalidade destes territórios, tem sido acompanhada por discursos antagónicos. Por um lado, um certo fatalismo e vitimização do capital de queixa que se vai acumulando e, por outro, um enaltecimento do lado virtuoso destes territórios através dos novos processos de revalorização, recriação e diversificação dos sistemas produtivos no âmbito das múltiplas iniciativas de desenvolvimento local no quadro das políticas europeias e nacionais.

A baixa densidade não sendo em si, uma restrição ex-ante, torna-se um problema ex-post, pela ausência de uma estratégia e aproveitamento económico dos recursos, tratando-se quase sempre de um problema estrutural de longo prazo e de um modelo de desenvolvimento ou de "não-desenvolvimento" geralmente assimétrico, difuso, invertebrado e híbrido (Covas 2013).

Neste sentido, o combate dos desequilíbrios territoriais é uma preocupação de várias décadas, pelo que desde os anos oitenta do século passado têm sido concebidas diversas estratégias e programas de revitalização, recuperação e valorização dos territórios rurais de baixa densidade, para a melhoria de bem-estar socioeconómico e ambiental das comunidades (Baltazar, 2018), agora também designados territórios do interior. Estas novas filosofias de desenvolvimento territorial e participado foram acompanhadas pela criação de estruturas que têm como fim a promoção do desenvolvimento local, sendo de realçar a mais recente Unidade de Missão de Valorização do Interior ${ }^{1}$, responsável pela implementação e supervisão de um conjunto de medidas no âmbito do Programa Nacional para a Coesão Territorial.

Nestes territórios do interior, os recursos existentes implicam a adoção de estratégias de desenvolvimento assentes nos fatores internos (forças e fraquezas), e externos (oportunidades e ameaças), onde o trabalho em rede e a cultura de parceria figuram como elementos essenciais no processo. De acordo 
com Baltazar \& Santos (2015, p. 210) "importa estimular a concretização de atuações coletivas de forma integrada [inteligência territorial adormecida], uma vez que as iniciativas de base local e regional de per si, sem que haja um modelo integrado originam a delapidação de recursos e o desaproveitamento de sinergias". Em territórios desta natureza ganha especial importância o papel do ator-rede, aquele que assume a função de cuidador e que possui a capacidade de criar consensos dentro de um espaço de debate público efetivo (Covas \& Covas, 2015), em que exista a capacidade para introduzir a noção de autolimitação da ação e dos interesses individuais de cada um. Como afirmam Covas \& Covas (2014; 2015) o ator-rede possui um papel crucial, na medida em que materializa o conceito de "administração dedicada", enquanto agente principal na mediação e intermediação no quadro de governança e pilotagem de um projeto comum que pode ser decisivo para o desenvolvimento de territórios do interior (Reis, 2017).

A materialização deste novo quadro de teorias de desenvolvimento territorial e participado, pode ser confirmado pelas novas lógicas e dinâmicas subjacentes ao modelo de desenvolvimento alternativo (Sharpley \& Telfer, 2015), estruturado em torno da valorização diferenciação e do potencial endógeno como forma de garantir um desenvolvimento harmonioso, sustentável e em prol das comunidades locais com o desenvolvimento de novas atividades produtivas ligadas ao lazer e turismo, saúde e bem-estar, produtos locais, entre outros - multifuncionalidade -, assente nos princípios de parcerias público-privadas e intervenções de enfoque ascendente, territorial, integradas e participativas (Ferrão \& Mourato, 2010).

Neste quadro, é possível verificar duas realidades contraditórias em torno do espaço rural, por um lado, um crescente aumento das políticas utilitaristas do mundo rural como "jardim da cidade" através de ações de preservação e conservação da paisagem e dos recursos materiais e imateriais, como, por outro, um crescente interesse e consumo cosmopolita, associado a difusão de modos de vida urbanos e de políticas viradas para o estímulo de outros setores atividade ligados à economia rural como o turismo, as indústrias criativas, a indústria agroalimentar e vinhos, as tecnologias de informação, entre outros.

Entre os diferentes setores de atividade, o turismo e o lazer, foram considerados estratégicos para a revitalização e diversificação económica dos territórios rurais, por vezes como a única alternativa para territórios com dificuldades estruturais como os territórios do interior, através do aproveitamento dos valiosos recursos naturais, paisagísticos e histórico-culturais. O desenvolvimento do turismo e do lazer nos territórios rurais tem sido um processo permanente e duradouro, proporcionado pelo abrandamento do turismo convencional, relacionado com o desenvolvimento de múltiplas atividades turísticas, as quais despertam novos interesses de procura e de deslocação a destinos turísticos alternativos.

Um aspeto marcante na valorização e reconversão das antigas funcionalidades destes territórios são os novos padrões de consumo e, os novos espaços que emergem com o novo turista e com o novo turismo (Poon, 2003), naquilo que é uma rutura com as práticas vigentes nas últimas décadas do século XX. $\mathrm{Na}$ opinião da autora, a afirmação deste novo turismo, por oposição ao turismo tradicional de massas, reflete-se na diversificação dos destinos e no desenvolvimento de produtos turísticos mais diversificados e personalizados. Em resultado da evolução e alteração dos gostos, das necessidades e das preferências do turista, surge o desejo sempre renovado de conhecer novos destinos, o desafio de viver experiências únicas que promovam a diferença (autenticidade, experiências únicas e personalizadas), verdadeiras e memoráveis com base em atividades distintas que o destino turístico deve proporcionar - novos produtos turísticos (Poon, 2003), "deslocando-se para locais aprazíveis e com pouca densidade turística" (Correia \& Carvalho, 2010, p. 119) como os territórios do interior. Na opinião dos autores, estamos perante territórios com especificidades e condições para o desenvolvimento e crescimento da atividade turística, nos quais, a escala e localização se distingue dos produtos e dos destinos tradicionalmente explorados e massificados.

Na prática, os novos comportamentos e hábitos do consumo turístico que emergem com o novo turista colocam novos desafios ao sistema turístico em matéria de estruturação da oferta e, em termos da configuração de novos lugares e destinos turísticos como os territórios do interior. Decorrente desta mutação, constata-se a emergência de novos segmentos de mercado como consequência dos estilos de vida, preferências e interesses do novo turista, traduzindo-se numa procura turística cada vez mais exigente, segmentada e em constante mudança.

Estas novas tendências implicam, no entanto, uma nova forma de estruturação, gestão e planeamento dos produtos e dos territórios rurais, anteriormente voltados para funções agrícolas, pressupondo uma visão estratégica, colaborativa e coordenada entre as políticas públicas e os diferentes atores públicos, privados e sociedade civil. Por outras palavras, poder-se-á afirmar que não basta existir apenas recursos turísticos, é necessário que exista um processo de transformação como acontece com qualquer outro produto (Reis, 2017). A produção turística é um elemento chave no sistema turístico, a sua importância é fundamental para a existência de uma oferta turística. Aliás, alguns dos elementos da oferta turística, só 
são alvo de procura quando englobados num produto turístico específico, para responder às necessidades e desejos dos consumidores.

De entre as diferentes aceções de produto turístico, podemos adotar a conceção de Medlik \& Middleton (1973), segundo os quais, um produto turístico é um conjunto de componentes tangíveis e intangíveis, centrados numa atividade específica e num destino concreto, daí que origina deslocações para seu consumo. Entre os bens tangíveis podemos encontrar tudo o que tem um carácter objetivo (os recursos, as infraestruturas, as superestruturas e os equipamentos), e, nos elementos intangíveis tudo o que tem um carácter subjetivo (a hospitalidade/acolhimento da comunidade local, os serviços, a imagem de marca, o preço) (Valls, 2003). De acordo com estas características, é possível identificar uma panóplia de produtos turísticos que procuram satisfazer as necessidades dos diferentes segmentos de mercado, com a incorporação de diferentes especificidades segundo os distintos grupos de consumidores, numa perspetiva de hipersegmentação da oferta turística.

Em Portugal, tem-se assistido nos últimos anos a um crescente aparecimento de novos produtos turísticos face ao tradicional produto turístico de sol e mar, sendo o caso do turismo de natureza, turismo cultural e paisagístico, turismo de saúde e bem-estar, turismo náutico, entre outros (MEE, 2013; MEI, 2007). Estes produtos podem existir de forma isolada ou coexistir com outros produtos turísticos, porém, a complementaridade entre produtos permite combater o problema das assimetrias regionais e da sazonalidade e simultaneamente valorizar e rentabilizar as potencialidades desaproveitadas em determinados territórios, como os do interior, tornando-os ativos diferenciadores, qualificados e emergentes. Esta visão integradora encontra-se presente nos diferentes discursos políticos, programas e documentos estratégicos como, por exemplo, os Programas Operacionais Temáticos e Regionais do Portugal 2020, as Estratégias Regionais de Especialização Inteligente e a Estratégia Turismo 2027 (TdP, 2017). No segundo documento estratégico, sobressai o alargamento da atividade turística a todo o território nacional e durante todo o ano, de forma a promover a coesão social, através de linhas de atuação específicas, entre as quais, a afirmação do turismo náutico - ativo diferenciador -, com a dinamização e valorização das infraestruturas, equipamentos e serviços de apoio dos portos, marinas e centros náuticos (TdP, 2017), mas em complementaridade com outros ativos como a natureza, o património histórico, a cultura e identidade, o clima e luz, entre outros.

De acordo com Verdet (2002), o turismo náutico pressupõe que as pessoas efetuem uma viagem cuja principal motivação é a realização de atividades náuticas, com objetivos recreativos e/ou de lazer ou desportivos/competição, praticados em grandes massas de água, como o mar, rios ou lagos. Nesta conceção, constata-se que o turismo náutico atravessa a fronteira do desporto, sendo por isso, possível classificar e/ou estruturar o turismo náutico em modalidades como a náutica de recreio e a náutica desportiva, para além de outras classificações como o turismo de cruzeiros, que variam segundo o principal motivo de viagem. $\mathrm{O}$ turismo náutico desportivo está associado a experiências baseadas em viagens realizadas com a motivação principal de realizar, ou participar, em competições náutico-desportivas (surf, windsurf, vela, kitesurf, canoagem, remo, pesca desportiva, etc.), por sua vez, o turismo náutico de recreio está relacionado com experiências de desportos náuticos ou de charter náutico, numa perspetiva de lazer e entretenimento (vela, windsurf, mergulho, remo, passeios de barco a motor) (THR, 2006).

Em Portugal, o turismo náutico, está à semelhança da realidade espanhola fortemente associado ao mar e às atividades de navegação (Verdet, 2002), isto, apesar das alterações registadas face há uns anos atrás e aos mais recentes esforços das políticas públicas para valorização das águas interiores (TdP, 2017). É indiscutível que Portugal possui no seu território um enorme potencial, quer no que concerne a águas do mar, quer no que diz respeito a águas interiores, ou seja, apresenta um conjunto de oportunidades que permitem a prática do turismo náutico e, a afirmação do país e de algumas regiões como destinos turísticos competitivos no mercado turístico europeu. Para isso é preciso criar condições em termos de instalações e equipamentos adequados para a prática de qualquer tipologia de turismo náutico, isto é, potenciar a oferta náutica.

Neste quadro, o Grupo Dinamizador do Portugal Náutico, avançou à semelhança de outros casos na Europa (França e Espanha), com um processo de certificação e promoção de Estações Náuticas em Portugal, nos últimos três anos (AEP, 2015). Apesar da concentração das Estações Náuticas em destinos de costa marítima, a criação de estações náuticas em territórios do interior, em planos de águas, rios, lagos e albufeiras de barragens, representam uma oportunidade de desenvolvimento do turismo náutico em destinos turísticos alternativos, nomeadamente os Centros Náuticos de Castelo de Bode, Lago de Alqueva - Moura e, o de Avis (AEP, 2015). Estes são três exemplos dos investimentos realizados nas áreas interiores para diversificação da oferta turística e, consequentemente, um conjunto de benefícios socioeconómicos para este tipo de territórios, de que destacamos no ponto seguinte o caso particular de Avis. 


\section{Apresentação de um caso: a Estação Náutica de Avis}

O município de Avis situa-se na NUT II Alentejo, sub-região do Alto Alentejo, fazendo fronteira com os municípios de Alter do Chão, Fronteira, Sousel, Ponte de Sor e Mora, ocupando uma área de 606 $\mathrm{Km}^{2}$ (Figura 1).

Figura 1: Localização geográfica do concelho de Avis - âmbito regional e concelhio
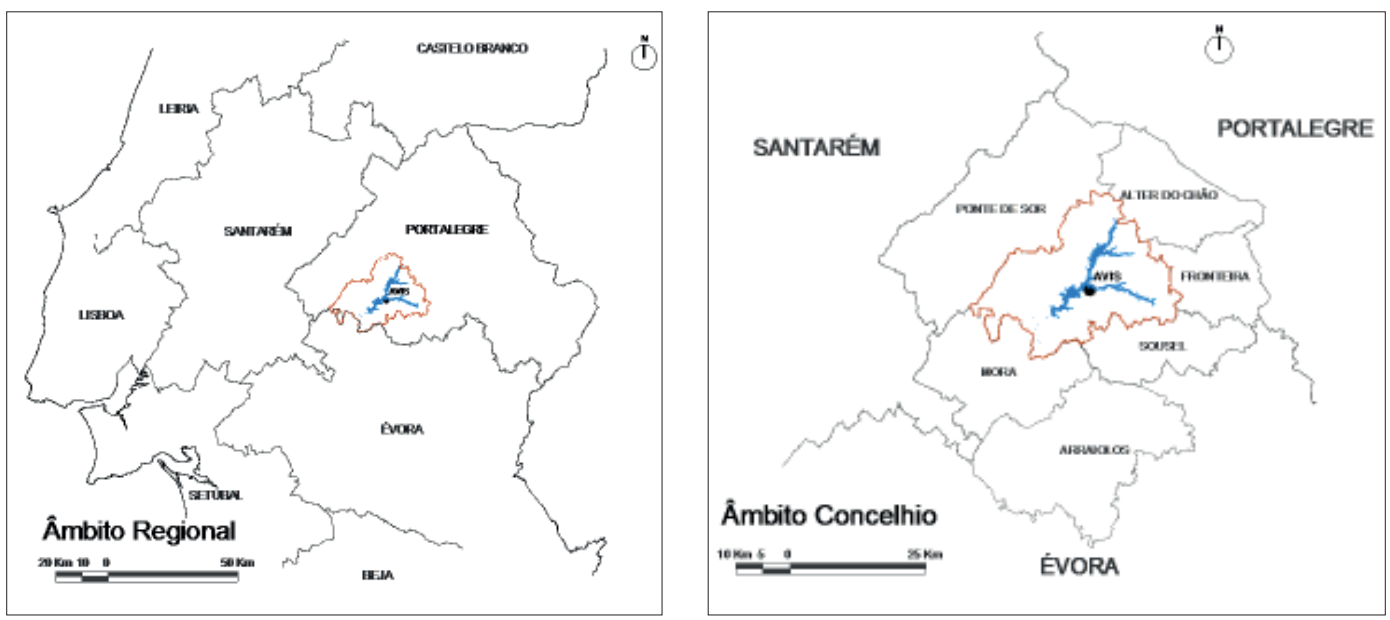

Fonte: Câmara Municipal de Avis, 2019

Na figura 1, destaca-se a extensão da albufeira do Maranhão, integrada na bacia hidrográfica do rio Tejo, com uma extensão $46 \mathrm{Km}$ e que se estende pela quase totalidade do território.

Este município apresenta características comuns a territórios de baixa densidade, é constituído por uma estrutura populacional envelhecida, com dificuldades na fixação da população jovem, em especial a população qualificada, e também regista dificuldades na captação de investimentos externos.

O município de Avis desde há longa data que considera a albufeira do Maranhão um recurso ativo do seu desenvolvimento, tendo aprovado em 1999 o Plano de Ordenamento da Albufeira do Maranhão (POAM). O principal objetivo foi estabelecer as normas necessárias à harmonização e à compatibilização das atividades proporcionadas por esta albufeira, com as finalidades de rega e de abastecimento público, tendo presente a valorização e salvaguarda dos recursos naturais. Por outro lado, este instrumento de planeamento contemplou o aproveitamento deste manto de água para o desenvolvimento de outras atividades como o lazer e o turismo (pesca; banhos e natação; navegação recreativa a remo, à vela e a motor; aprendizagem e treino de esqui aquático; competições desportivas, salvo quando pressuponham a utilização de embarcações motorizadas; entre outras).

O plano previu ainda limites ao nível do uso do solo e da construção na área abrangida e, incluiu uma visão orientadora das ações de natureza pública/privada que vieram a ocorrer no território, em especial as intervenções de natureza pública municipal que tiveram lugar no Complexo do Clube Náutico. Ao longo dos anos, foram construídas infraestruturas de apoio ao lazer e à prática de desportos náuticos, tais como: praia fluvial, parque de merendas, bar/restaurante, parque infantil, cais de embarque para desportos náuticos, parque de campismo, hangar náutico e pista de remo.

Em 2018, tendo em atenção as orientações inscritas nos principais documentos estratégicos nacionais e regionais para o setor do turismo, o município avançou com a apresentação de uma candidatura de certificação da Estação Náutica de Avis.

A candidatura teve como principal objetivo a valorização dos recursos náuticos, através da estruturação de uma rede de atores com intervenção nas diversas etapas do desenvolvimento territorial para contrariar "a falta de tradição no trabalho em rede. Pelo facto de não ser usual este tipo de inter-relação, o trabalho colaborativo tem que ser incentivado de modo a promover o aproveitamento das capacidades do próprio território e dos recursos disponíveis" (Município de Avis, 2018, p. 13). 
Num primeiro momento, a concretização deste objetivo central passou pelo desenho de uma oferta turística assente no desporto náutico e circunscrita apenas ao Complexo do Clube Náutico. Num segundo momento e, em 2018 após a apreciação da candidatura pela Comissão de Avaliação ${ }^{2}$, o âmbito territorial alargou-se ao município e a outros atores, com vista ao desenvolvimento de um produto turístico integrado, tendo a componente do náutico como elemento agregador da rede. O desenvolvimento deste produto turístico integrado passa também pela valorização de outros recursos endógenos, nomeadamente: património natural e histórico, cultural local e gastronomia e vinhos.

A rede de parceria é, atualmente, constituída por 22 entidades, estruturada de acordo com o modelo da quadrupla hélice ${ }^{3}$ - quatro grandes áreas de intervenção -, tal como se constata na figura seguinte:

Figura 2: Parceria da Estação Náutica de Avis

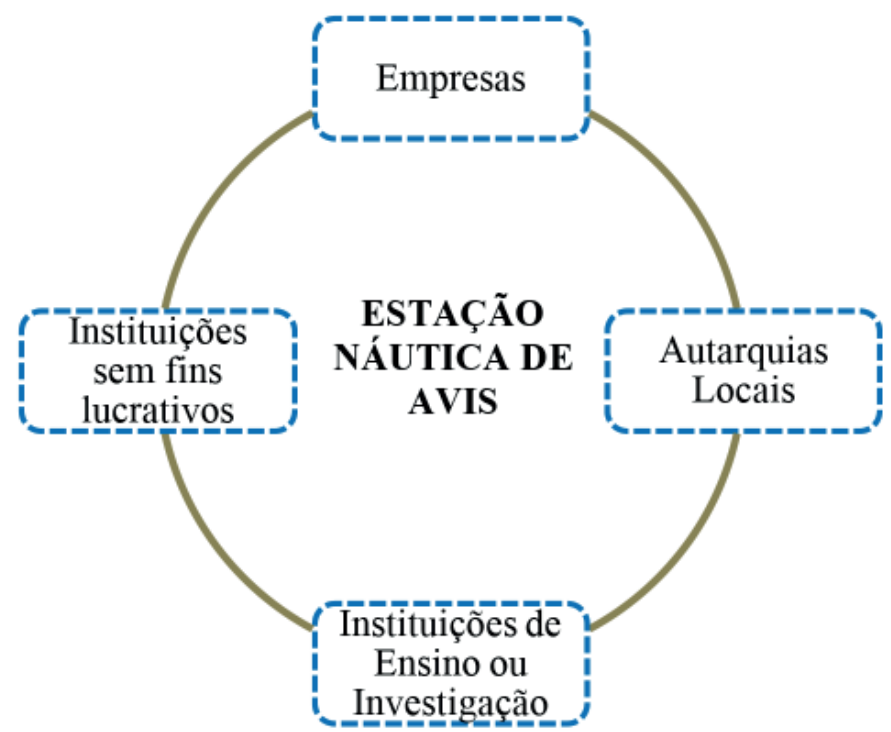

Fonte: elaboração própria

$\mathrm{Na}$ formulação da candidatura estavam envolvidos 12 parceiros: quatro entidades de natureza pública, seis empresas e duas entidades do setor social. Aquando do ato de certificação da EN, esta já contava com mais de duas dezenas de parceiros, sendo de destacar o reforço das instituições sem fins lucrativos e das empresas. Numa perspetiva de promover a inovação e o conhecimento a parceria considerou necessário o envolvimento da Universidade de Évora (através do Centro de Investigação CICS.NOVA.UÉvora) na rede.

Salienta-se que, na parceria se encontram estruturas de poder com influência quer ao nível local e municipal, quer regional, como sejam a freguesia, o município e a Entidade Regional de Turismo do Alentejo e Ribatejo.

No que se refere aos bens ou serviços transacionados pelas empresas parceiras, identificam-se as seguintes atividades: alojamento, restauração, animação turística, enoturismo, exploração agrícola, cinegética, produção de azeite e arte contemporânea.

A parceria contempla um leque diversificado de atores, ultrapassando o âmbito local ao incorporar empresas extra-concelhias (duas) e entidades de âmbito supramunicipal (quatro), o que demonstra uma elevada heterogeneidade e uma diversidade de recursos com capacidade de mobilização, em torno de um objetivo comum.

A criação de um produto turístico integrado implica a adoção de uma cultura de parceira, a partir de estratégias coletivas de intervenção territorial, ultrapassando assim um dos principais problemas identificados em sede de candidatura, com a aplicação de metodologias participativas inovadoras. 


\section{Metodologia participativa: do recurso endógeno ao produto turístico integrado}

A concretização do objetivo inerente ao processo de certificação da Estação Náutica - produto turístico integrado -, passou pela adoção de metodologias participativas. Esta escolha resultou de uma análise cuidada e objetiva ao território, aos atores e às relações entre estes, tendo em consideração as teorias atrás mencionadas sobre o papel da participação nos processos de desenvolvimento. O sucesso destes processos depende da participação (direta ou indireta) dos atores que têm capacidade de influenciar a tomada de decisão sobre as iniciativas de mudança a adotar, e, sobre os recursos a mobilizar, com o objetivo de aumentar a relevância, a eficácia e os efeitos sustentáveis de uma intervenção.

Este processo permite obter melhores resultados e uma melhor governança, concorrendo para que sejam implementadas deliberações mais apropriadas, visto que os decisores e outros intervenientes ficam a dispor de informações mais completas, referentes a preferências, circunstâncias, valores e perspetivas. Conhecimentos esses, obtidos por intermédio de contributos expendidos pelos(as) participantes nos momentos de interação em que procuram de acordo com a sua perspetiva, aprimorar o processo de decisão.

A participação concorre assim para fomentar o capital social que consiste segundo Roseland (2005, p. 9) no conjunto de "relações, redes e normas que facilitam a acção colectiva" ou o "saber, conhecimentos, e padrões de interacções partilhados que um grupo de pessoas trás para qualquer actividade produtiva", neste caso um processo de Desenvolvimento Local, Integrado e Sustentável.

\subsection{O contributo da metodologia world café}

Tendo em atenção os pressupostos enunciados e atendendo à fase do projeto (período após a certificação da ENA), foi elaborado pela equipa de investigadores do CICS.NOVA.UÉvora em articulação com o município, um roteiro cronológico que incidiu sobre os seguintes itens: recapitulação dos antecedentes, desafios no presente, onde queremos estar e, como vamos lá chegar no futuro a médio prazo, exercício que culminou com o agendamento de várias iniciativas.

De entre essas iniciativas sobressai a realização de um encontro de parceiros, cuja configuração foi transposta para uma Matriz de Enquadramento Lógico (MEL), na qual ficaram inscritas as duas opções fundamentais que constam no quadro seguinte:

\section{Quadro 1: Matriz de Enquadramento Lógico do Encontro de parceiros, em Avis}

\begin{tabular}{|l|l|}
\hline Finalidade & $\begin{array}{l}\text { Acrescentar valor ao conteúdo da candidatura, visando a recolha de contributos } \\
\text { para a respetiva implementação. }\end{array}$ \\
\hline Objetivo geral & $\begin{array}{l}\text { Fomentar o espírito de equipa (team bulding), mediante a realização de um Focus } \\
\text { Group, para a criação de um produto turístico integrado. }\end{array}$ \\
\hline
\end{tabular}

Fonte: elaboração própria

Para concretização do objetivo geral optou-se pela realização de um focus group ${ }^{4}$ ou grupo focal com recurso à microestrutura designada por world café. O world café é uma metodologia participativa para recolha de dados qualitativos em diferentes áreas de conhecimento como a saúde, a ação social, o ensino, entre outras (Bussolotti, Aranha \& Cunha, 2018; Machado \& Passos, 2017).

Esta técnica visa potencializar diálogos e, viabilizar a construção coletiva dos participantes em torno de um entendimento comum sobre uma questão/problema que é apresentada como tema central de debate (Brown \& Isaacs, 2008). Ferreira \& Almeida (2016) apontam mesmo como principal vantagem, a construção coletiva para determinados problemas de uma sociedade e/ou território, conduzindo a soluções mais diversificadas e adequadas do que outras técnicas tradicionais. De acordo com as mesmas autoras, não está isenta de dificuldades podendo apresentar constrangimentos ao nível da mobilização dos participantes.

Tendo presente a análise efetuada à temática da candidatura, ao objetivo geral e às considerações da entidade promotora (município de Avis), nomeadamente o facto de existirem atores que não se conheciam ou que não tinham qualquer tipo de interação, tornou-se importante encontrar mecanismos alternativos que desencadeassem um maior diálogo entre todos. 
Em termos de tendências de investigação em turismo, verifica-se uma rutura com as abordagens tradicionais e uma crescente adoção de abordagens qualitativas no estudo do fenómeno turístico nas mais diversas dimensões, particularmente no que se refere aos problemas e aos processos de âmbito territorial (Phillimore \& Doodson, 2004; Junek \& Killion, 2012). Apesar do turismo, até ao momento, não ser uma área com evidências de aplicação desta metodologia, considerou-se ser a técnica mais adequada para o estudo de caso em questão e, para a concretização do objetivo traçado.

De acordo com Machado \& Passos (2017) a utilização e o sucesso desta técnica passa pelo cumprimento de um conjunto de princípios orientadores: i) definição do contexto; ii) criação de uma atmosfera acolhedora; iii) lançamento das questões temáticas a explorar; iv) articulação das diferentes ideias e perspetivas sobre as questões; v) escuta coletiva e partilha de ideias.

A operacionalização da metodologia implicou a construção de um conjunto de quatro questões temáticas, a divisão dos diferentes participantes das entidades da parceria por grupos, a designação de moderadores para cada um dos temas e os facilitadores da sessão.

A utilização desta metodologia exige uma preparação cuidada da sessão, um conhecimento prévio dos elementos que irão participar e a formulação prévia das questões a colocar à discussão do grupo, de forma a alcançar o objetivo proposto.

A primeira ação preparatória realizada pela equipa de facilitadores (grupo de investigadores do Centro de Investigação) foi a enumeração dos parceiros (atores na sessão), distribuição e constituição de subgrupos heterogéneos de acordo com as áreas de atividade e de afiliação nas entidades parceiras. Foram constituídos quatro subgrupos e cada um deles era composto por quatro participantes. Nesta etapa foram definidas quatro questões, a sua formulação teve como base: o interesse dos temas colocados à discussão para os participantes e a sua ordenação mediante um roteiro estratégico (de onde vimos? o que somos? para onde queremos ir?). Foi criada uma grelha de registo das ideias dos participantes, a preencher por cada moderador.

A identificação e preparação do local de realização da sessão visou a criação de um ambiente acolhedor e informal e, em complemento, verificaram-se as necessidades de material a utilizar na sessão.

A sessão iniciou-se com a apresentação dos facilitadores, dos objetivos do encontro no âmbito da Estação Náutica de Avis, da metodologia de trabalho e da chamada dos participantes (apresentação individual e da entidade que representavam, com a utilização de três palavras-chave para caracterizar a área de atuação da entidade), e, entrega dos respetivos cartões de identificação a todos os presentes.

Os facilitadores informaram os participantes sobre a constituição dos subgrupos e estes deslocaram-se para as quatro "mesas de café" organizadas por temáticas: A - recursos endógenos; B - produto turístico integrado; C - complementaridades ao produto turístico e D - modelo de governança. Os quatro moderadores integraram as respetivas mesas temáticas, acompanhados pelo material necessário (toalha de mesa em papel, marcadores, post-its e grelha de registo) à dinâmica do world café.

A dinâmica dos cafés temáticos iniciou-se através do estímulo do moderador que lançou e registou a questão na toalha de papel, avançando com algumas ideias, subtemas para debate envolvendo todos os participantes na discussão e, registando na grelha os diferentes contributos. O apelo recorrente à criatividade e incentivo à partilha de ideias, associando-se à capacidade de escuta coletiva, operacionalizou-se no registo das ideias-chave nos post-its colados nas toalhas de mesa (cada subgrupo utilizou post-its coloridos para facilitar a identificação dos contributos dos demais subgrupos). Ao fim de 20 minutos, os subgrupos terminaram a discussão e rodaram para a mesa seguinte.

O moderador de cada mesa ao receber o novo subgrupo, partilhou os principais contributos/ideias do subgrupo anterior e, incentivou-o a articular as ideias desenvolvidas nas conversas das mesas anteriores e a refletir sobre os diversos contributos apresentados por cada participante. Enquanto isto, os facilitadores foram monitorizando a dinâmica de cada uma das mesas, esclarecendo dúvidas e estimulando a reflexão de cada participante e, verificando o período de tempo estipulado para cada ronda.

Depois de todos os subgrupos passarem pelas quatro mesas, cada moderador procedeu à partilha das ideias apresentadas e discutidas em cada café temático, em plenário, dando ao grupo a oportunidade uma reflexão conjunta final, validando os demais contributos/ideias.

A utilização da metodologia world café, descrita atrás, revela-se inovadora no domínio do turismo porque permite mobilizar um conjunto de atores em torno de um objetivo comum. Esta radica no princípio da polinização cruzada que visa desenvolver uma conexão entre os participantes na recolha de contributos de resposta para cada questão temática, refletida numa rotatividade dos subgrupos, presentes em cada mesa temática, em torno das questões em discussão. Os contributos recolhidos em subgrupo são desde logo objeto de apreciação pelos restantes elementos, para um primeiro nível de validação. Após o 
primeiro momento de diálogo, em cada mesa permanece o moderador e rodam os restantes elementos para a mesa seguinte com vista à discussão de uma nova temática, levando para o efeito ideias-chave, perguntas e temas para as suas novas conversas. As sucessivas rondas dos subgrupos de conversação possibilitam a polinização dos participantes com os contributos apresentados nas conversas anteriores, conectando ideias e reflexões.

Esta capacidade de construir estratégias coletivas no domínio do turismo a partir dos contributos dos diferentes atores, assume particular relevância na interpretação dos fenómenos turísticos no momento atual.

Nesta perspetiva, a abordagem qualitativa emerge como uma alternativa aos tradicionais trabalhos quantitativos, na medida em que tem vindo a alcançar aceitação e prestígio em diversos domínios, como o turismo (Riley \& Love, 2000). Estes autores defendem ainda que, não obstante o turismo necessitar de estudos quantitativos para se tornar uma indústria competitiva, existem outras dimensões a analisar e a compreender que, pela sua especificidade, implicam o recurso à abordagem qualitativa.

Este tipo de metodologia permite uma constante redefinição da abordagem analítica, mediante os diversos momentos de trabalho conjunto em torno de um objetivo comum, com recursos pouco dispendiosos e celeridade nos resultados. A técnica do world café permite a concentração de um conjunto de atores, num mesmo espaço, e no mesmo momento, mas tal não é sinónimo de condicionalismo à liberdade dos participantes em exporem as suas perspetivas ou ideias para a construção da estratégia coletiva de intervenção. Este princípio está refletido na seção seguinte.

\subsection{Análise e discussão dos dados recolhidos}

Como já foi referido anteriormente, o presente artigo apresenta as principais reflexões de um conjunto de atores envolvidos no desenho de estratégias de desenvolvimento de um produto turístico integrado - Estação Náutica de Avis -, num destino alternativo como o concelho de Avis através da adoção e aplicação de metodologias participativas.

$\mathrm{O}$ estudo de caso teve como principal enfoque as reflexões dos participantes nas 4 mesas temáticas, a recordar: A - recursos endógenos; B - produto turístico integrado; C - complementaridades ao produto turístico e $\mathrm{D}$ - modelo de governança.

No que diz respeito à primeira mesa temática, os participantes, reconheceram e identificaram de forma exaustiva os recursos endógenos do território em questão, por vezes, mal aproveitados pelos atores dos territórios no desenvolvimento de atividades de turismo e de lazer, e que são cada vez mais valorizados na revitalização de territórios de matriz rural. Entre os diferentes subgrupos foi consensual a existência de diversos recursos com potencial de atração para o desenvolvimento de valor acrescentado do produto turístico integrado, nomeadamente os recursos naturais e os recursos culturais. Entre os recursos naturais consta a avifauna, cinegética, natureza, água, céu, clima e tranquilidade. A par destes, os participantes consideram importante valorizar e preservar os recursos culturais, designadamente o património histórico, construído e cultural, incluindo edifícios e saberes-fazer tradicionais, os quais configuram na perspetiva dos atores participantes, âncoras fundamentais para o desenvolvimento de atividades como o turismo e, em particular novos produtos turísticos destinados a captar segmentos da procura turística mais exigentes.

Nesta sequência, os participantes identificaram na segunda mesa temática os diferentes produtos locais existentes no território e refletiram sobre as estratégias a adotar para integrar os diferentes produtos locais num produto turístico global. De acordo com os participantes (figura 3), o incremento deste produto global passa pela criação de produtos únicos e diferenciados, experiências temáticas e pela conceção de pacotes turísticos, envolvendo e mobilizando os diferentes recursos endógenos e atores do território no desenvolvimento de um produto turístico compósito e atrativo. Por isso, defendem a criação de uma plataforma de gestão virtual e física, para promoção e divulgação do produto turístico, integrando um sistema de reservas on-line, uma loja virtual de produtos locais, uma central de compras para os consumidores dos diferentes produtos, experiências e pacotes turísticos, tendo em vista a uniformização da oferta turística. Esta vertente virtual é acompanhada, no território, de uma componente física, onde tem lugar o acolhimento de visitantes, funcionando como uma porta de entrada na Estação Náutica.

Para tal, considerou-se pertinente questionar os atores do território sobre o tipo de complementaridades empresariais a criar e/ou desenvolver para conferir atratividade turística à Estação Náutica, tendo como princípios orientadores as reflexões anteriores. Os subgrupos estabeleceram três grandes vetores de intervenção para estimular essas complementaridades, designadamente cultura de parceria, maximização de recursos e, venda/comercialização. 


\section{Figura 3: Mapa conceptual da articulação dos diferentes produtos locais num produto turístico global}

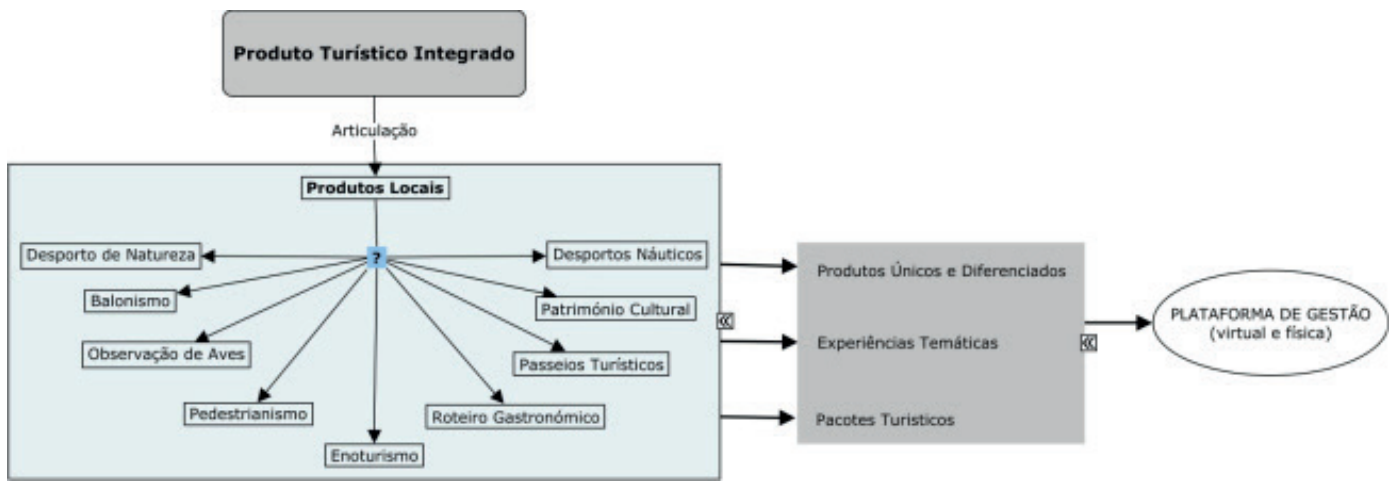

Fonte: elaboração própria com base nos dados do focus group, 2019

Foi considerado desejável a criação de uma cultura de parceria através do estímulo ao interconhecimento entre os diferentes atores turísticos (diretos e indiretos), com a realização de visitas inter-parceiros para apresentação dos projetos individuais, recursos (físicos, humanos, tecnológicos, etc.) e produtos/ serviços para o consumidor e/ou visitante, sendo um primeiro passo para a criação de uma matriz de trabalho conjunto entre os atores, suportado por um guia de orientação/apoio para os atuais e potenciais empresários e organizações. Contudo, alguns veem a criação de complementaridades segundo lógicas de maximização de recursos ao nível dos transportes entre zonas de trânsito do consumidor (por exemplo, entre o principal aeroporto do país e o concelho de Avis), particularmente nos segmentos turísticos orientados para a prática de atividades náuticas; a comunicação do produto turístico é para os participantes um elemento estruturante nos princípios de complementaridade empresarial, de tal modo que estabelecem alguns instrumentos a adotar a curto e médio prazo, nomeadamente: apresentação pública do projeto Estação Náutica no ambiente interno e externo do sistema, criação da imagem âncora MARCA AVIS, organização/promoção de press trips (operadores turísticos, agências de viagens e bloggers) e criação de uma newsletter; a maximização dos recursos passa ainda pela animação territorial com a criação de uma agenda comum e de eventos turísticos únicos no território, incutindo lógicas diferenciadoras neste destino turístico alternativo.

$\mathrm{Na}$ perspetiva dos participantes, só através destas complementaridades será possível o produto turístico ganhar competitividade e capacidade de diferenciação face aos demais produtos concorrentes. Neste contexto, defendem a adoção dos princípios de complementaridade na ótica da venda/comercialização e distribuição do produto turístico, desde os intermediários até aos consumidores. E para que isto aconteça, é essencial que seja desenhado um plano integrado de atividades, de forma a assegurar as múltiplas visões e estratégias dos atores do território na valorização dos recursos e produtos locais do território, no contexto de um produto turístico global mas, simultaneamente, afirmando-se como elemento diferenciador num destino turístico alternativo.

A complexidade deste processo levou, por isso, à reflexão sobre o modelo de governança capaz de dar continuidade ao trabalho em rede, visando a cooperação entre todos os atores públicos e privados. Das diferentes reflexões dos subgrupos na última mesa temática salientam-se dois possíveis modelos de gestão: associação sem fins lucrativos ou associação empresarial e, em alternativa, uma Cooperativa de Responsabilidade Limitada (figura 4).

No caso da segunda proposta, a liderança deverá ser assumida pelo município enquanto ator-rede e/ou por um técnico de turismo da Câmara Municipal de Avis. Relembramos aqui as palavras de Covas (2018) sobre a missão do ator-rede: fomentar a identificação com o território; trabalhar para a efetiva territorialização das políticas e aproveitar todas as oportunidades para criar capital social - cooperatividade interna -, promovendo a confiança e a cooperação entre os diversos nós da rede com vista a alcançar o bem comum. $\mathrm{O}$ ator-rede deve assumir o papel de mediador, capaz de gerar consensos em prol de um novo espaço público que pode ser de consumo ou de visitação turística (Reis, 2017). 
Figura 4: Modelos de gestão para dinamização do trabalho em rede

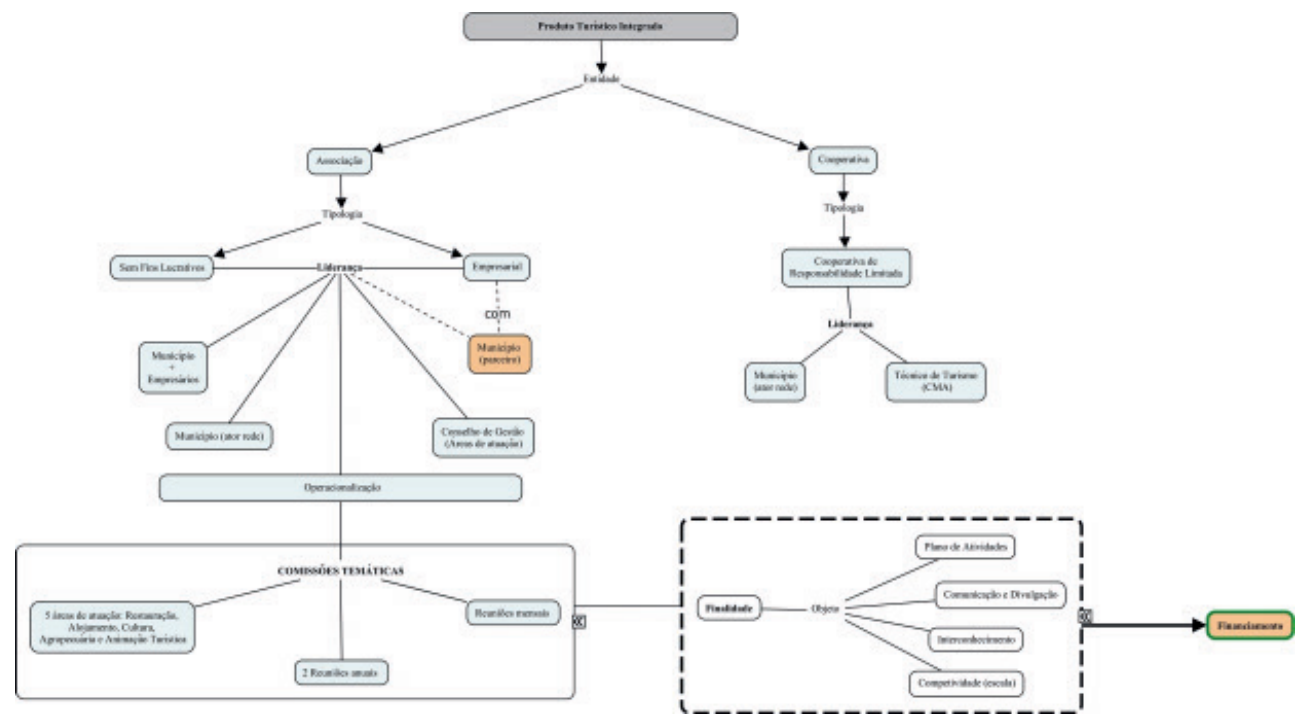

Fonte: elaboração própria com base nos dados do focus group, 2019

Na modalidade de associação, o município sobressai como ator-rede, quer na coordenação da parceria com os empresários do território, quer na ligação entre os diferentes nós do sistema (entidades parceiras). Em termos de operacionalização, a coordenação da rede deverá contar com o apoio direto de uma comissão temática, um sistema equilibrado entre entidades parceiras, constituída por elementos das cinco principais áreas de atividade no território (restauração, alojamento, cultura, agropecuária e animação turística), os quais deverão reunir com alguma regularidade (reuniões mensais e/ou pelo menos duas reuniões anuais). Esta comissão temática, por sua vez, assumirá um papel de enorme relevância no desenvolvimento de determinado tipo de tarefas como o plano de atividades, comunicação e divulgação, interconhecimento e fomento da competitividade, visando o acesso ao financiamento em processos de investimento no território.

Os resultados em torno das quatros questões permitem-nos concluir, no que se refere aos diferentes aspetos-chave, para uma conceção muito ligada à ideia de projeto, associado ao processo de candidatura para certificação da Estação Náutica, não se registando ainda outro tipo de abordagem que aponte para novas lógicas de conceção de um produto turístico integrado, apesar da tomada de consciência por parte de alguns dos atores.

\section{Conclusões}

Tal como sucede com a generalidade dos territórios de baixa densidade, o concelho de Avis, localizado no interior de Portugal, tem vindo a ser penalizado pelas tendências desfavoráveis inerentes a este tipo de territórios, que apresentam a par de um conjunto de pontos fracos, um outro conjunto de diversos pontos fortes / potencialidades.

O aproveitamento destes pontos fortes para criação de condições que possibilitem proporcionar a melhor qualidade de vida às populações locais, tem vindo a ser uma preocupação multinível, o que se consubstanciou no princípio da subsidiariedade, e em processos de desenvolvimento de dominante bottom up.

Um conjunto de circunstâncias favoráveis (internas e externas), originou que, no concelho de Avis, fosse gizada e apresentada a candidatura para a certificação de uma Estação Náutica, que foi aprovada, após concordância dos promotores em se comprometerem a desenhar, desenvolver e implementar um produto turístico integrado.

Este repto veio reforçar a exigência do envolvimento dos atores locais na efetivação das atividades requeridas para o sucesso do projeto. 
Para aprofundamento das questões em aberto, foi lançado aos referidos atores o desafio de aderirem a iniciativas que, pela relevância dos seus objetivos, demandam a utilização de uma metodologia participativa que alavanque as potencialidades da inteligência coletiva.

Uma primeira aplicação desta metodologia foi testada num momento fulcral para o futuro do projeto, pois tratava-se então de esclarecer e motivar os atores locais para aderirem com os seus contributos, no sentido de se alcançar um futuro mais promissor.

Os resultados que foi possível mensurar objetivamente ( $n^{\circ}$ de participantes, assiduidade), e a avaliação obtida a partir das respostas dos(as) participantes, permitiram constatar que a metodologia participativa constituiu um fator crítico de sucesso para a concretização do projeto, o que implica a atenção das entidades parceiras vocacionadas para a formação, na responsabilidade que lhe assiste, de promoverem a capacitação de facilitadores com competências adequadas para ampliar, através da participação, a aplicação da inteligência coletiva em processos de desenvolvimento local, simultaneamente endógeno, integrado e sustentável.

\section{Bibliografia}

AEP 2015. Portugal Náutico: um mar de negócios, uma maré de oportunidades. Lisboa: Associação Empresarial de Portugal.

Baltazar, M. S. \& Santos, M. O. 2015. "Empreendedorismo em Territórios de Baixa Densidade Populacional - o caso particular do Projeto WINNET 8". In Carvalho, L.; Dominguinhos, P.; Baleiras, R. \& Dentinho, T. (Eds.), Empreendedorismo e Desenvolvimento Regional - Casos Práticos (pp.203-227). Lisboa: Edições Sílabo.

Baltazar, M. S. 2018. "Desigualdades Territoriais em Portugal: da conceptualização às políticas públicas de desenvolvimento regional”. In Gomes, S., Duarte, V., Ribeiro, F., Cunha, L., Brandão, A. \& Jorge, A. (Coords.), Desigualdades Sociais e Políticas Públicas - Homenagem a Manuel Carlos Silva (pp. 233-258). V.N. de Famalicão: Húmus Editora.

Baltazar, M. S., \& Santos, M. 2014. Experiências de Empreendedorismo como contributo para a revitalização dos Territórios de Baixa Densidade. In 20th APDR Congress - Renaissance of the Regions of Southern Europe. Disponível em: https://dspace.uevora.pt/rdpc/handle/10174/12829 (acesso:10 de fevereiro de 2019).

Brown, J., \& Isaacs, D. 2008. "The World Café: Awakening Collective Intelligence and Committed Action”. In M. Torvey (Eds.), Collective Intelligence: Creating a Prosperous World at Peace (pp.47-53). Oakton: Earth Intelligence Network.

Carmo, R. 2014. Sociologia dos Territórios. Teorias, Estruturas e Deambulações. Lisboa: Editora Mundos Sociais.

Correia, J. \& Carvalho, P. 2010. “Turismo e desenvolvimento rural. O caso do Piódão (Aldeias Históricas de Portugal)". Cadernos de Geografia, 28/29: 117-130.

Covas, A. 2013. " Os territórios de Baixa Densidade e o próximo período de programação plurianual 2014-2020”. In Workshop Temático «Territórios de Baixa Densidade». Disponível em: http://webb.ccdr-a.gov. pt/index.php?option=com_content\&view=article\&id=338\&Itemid=309 (acesso: 22 de março de 2019).

Covas, A. \& Covas, M. 2014. Os territórios-rede. A inteligência territorial da $2^{a}$ ruralidade. Lisboa. Edições Colibri

Covas, A. \& Covas, M. 2015. Multiterritorialidades I. Temas e problemas de governança e desenvolvimento territoriais. Lisboa. Edições Colibri

Covas, A. 2018. A valorização do interior: o ator-rede, o cuidador dos territórios. In Jornal Público, 7 de fevereiro. Disponível em: http://www.publico.pt/2018/02/07/sociedade/opiniao/a-valorizacao-do-interior-o-atorrede-o-cuidador-dos-territorios-1802056 (acesso: 18 de abril de 2019).

Douillet, A. C., \& Lefebvre, R. 2017. Sociologie politique du pouvoir local. Paris: Armand Colin.

Ferrão, J. \& Mourato, J. (2010). "A avaliação de políticas públicas como factor de aprendizagem, inovação institucional e cidadania. O caso da política de ordenamento do território em Portugal”. Revista Brasileira de Estudos Urbanos e Regionais, 12 (1): 9-28.

Ferreira, V. \& Almeida, H. 2016. Kit de ferramentas para diagnósticos participantes. Coimbra: CES.

Healley, P. 1998. "Building institucional capacity through collaborative approaches to urban planning". Environment and Planning A, 30(9): 1531-1546.

Junek, O. \& Killion, I. 2012. "Grounded theory". In Dwyer, L.,A. \& Seetaram, N. (Eds.), Handbook of Research Methods in Tourism: Quantitative and Qualitative Approaches (pp.325-338). UK: Edward Elgar Publishing. 
Machado, M. \& Passos, M. 2017. "O uso do world café como método de pesquisa junto às equipas de saúde". In Atas do $6^{\circ}$ Congresso Ibero-Americano de Investigação Qualitativa. Disponível em: https:// proceedings.ciaiq.org/index.php/ciaiq2017/article/view/1280 (acesso: 16 de março de 2019).

Medlik, S. \& Middleton, V. 1973. "The tourism product and its marketing implications". International Tourism Quarterly, 3: 28-35.

MEE 2013. Plano Estratégico Nacional de Turismo 2013-2015 (PENT) - Revisão do Plano de Desenvolvimento do Turismo no Horizonte de 2015. Lisboa: Ministério da Economia e do Emprego.

MEI 2007. Plano Estratégico Nacional do Turismo (PENT). Lisboa: Turismo de Portugal, I.P.

Morgan, D. L. 1996. "Focus group”. Annual Review Sociology, 22: 129-152.

Morgan, D. L. 1997. Focus group as qualitative research $\left(2^{\mathrm{a}}\right)$. California: Sage Publications.

Município de Avis 2018. Estações Náuticas de Portugal - Formulário de Candidatura.

Phillimore, J. \& Goodson, L. 2004. "Progress in qualitative research in tourism : epistemology, ontology and methodology". In Phillimore, J. \& Goodson, L. (Ed.), Qualitative Research in Tourism : ontologies, epistemologies and methodologies (pp. 3-29). London : Routledge.

Poon, A. 2003. "Competitive Strategies for a «New Tourism»". In Cooper, C. (Eds.), Aspects for Tourism: Classic Reviews in Tourism (pp.130-142). Clevedon: Channel View Publications.

Reis, P. 2017. Turismo, Planeamento e Desenvolvimento Regional-Estratégias de Intervenção para a Rede das Aldeias Históricas de Portugal. Tese de doutoramento. Coimbra: Universidade de Coimbra.

Riley, R. \& Love, L. 2000. "The State of Qualitative Tourism Research". Annals of Tourism Research, 27(1): 164-413.

Roseland, M. 2005. Toward Sustainable Communities: Resources for Citizens and Their Governments. Canada: New Society Publishers.

Sharpley, R. \& Telfer, D. J. (org.) 2015. Tourism and Development, Concepts and Issues (2a). Bristol: Channel View Publications.

TdP 2017. Estratégia Turismo 2027. Lisboa: Turismo de Portugal, I.P.

THR 2006. 10 Produtos Estratégicos para o Desenvolvimento do Turismo em Portugal - Turismo Náutico. Lisboa: Turismo de Portugal, I.P.

Valls, J. 2003. Las claves del mercado turístico. Cómo competir en el nuevo entorno. Bilbao: Ediciones Deusto.

Verdet, A. 2002. Puertos desportivos: repercusión de su administración y gestión en el desarrollo del turismo náutico. Estrategias para el caso de la Costa del sol. Tese de doutoramento. Málaga: Universidade de Málaga.

Van Horne, C., Dutot, V. 2017. "Challenges in Technology Transfer: An Actor Perspective in a Quadruple Helix Environment”. The Journal of Technology Transfer, 42(2): 285-301.

Resolução do Conselho de Ministros n.117/99, de 6 de outubro de 1999 - Aprovação do Plano de Ordenamento da Albufeira de Maranhão.

Resolução do Conselho de Ministros n.3/2016, de 22 de janeiro de 2016 - Criação da Unidade de Missão para a Valorização do Interior.

\section{Notas}

Criada pela Resolução do Conselho de Ministros n.3/2016, de 22 de janeiro de 2016.

Associação Empresarial de Portugal (AEP) em cooperação com a Fórum Oceano.

De acordo com o sistema de inovação quádrupla hélice, a estrutura económica de um país é baseada em quatro pilares: empresas, governo, universidade e sociedade civil, atores que visam favorecer um ecossistema integrado de inovação onde qualquer forma de criatividade se pode desenvolver (Van Horne e Dutot, 2017).

Tanto o conceito da tripla hélice como a abordagem da quádrupla hélice baseiam-se na ideia de que a inovação é o resultado de um processo interativo envolvendo diferentes esferas de atores, cada um contribuindo de acordo com sua função "institucional" na sociedade. Os protagonistas tradicionais da tripla hélice são universidade, indústria e governo. A sociedade civil é a esfera adicional incluída na quádrupla hélice, enquanto que na já denominada quíntupla hélice se realça a abordagem socioecológica dos ambientes naturais da sociedade com o desiderato de promover um desenvolvimento sustentável.

4 Consiste numa técnica de investigação de recolha de dados, efetuada através da interação de um grupo sobre um tópico apresentado por um facilitador, e abrange três componentes essenciais: i) ser um método de investigação dirigido à recolha de dados; ii) considerar a interação durante a discussão do grupo, como a fonte dos dados; e, iii) reconhecer o papel ativo do facilitador na dinamização da discussão do grupo para efeitos de recolha dos dados (Morgan, 1996, 1997).

Recibido:

$31 / 05 / 2019$

Reenviado:

$17 / 07 / 2020$

Aceptado:

$16 / 09 / 2020$

Sometido a evaluación por pares anónimos 